\title{
Probabilistic models for mechanical properties of prestressing strands
}

\author{
Luciano Jacinto $^{\mathrm{a}, *}$, Manuel Pipa ${ }^{\mathrm{b}}$, Luís A.C. Neves ${ }^{\mathrm{c}}$, Luís Oliveira Santos ${ }^{\mathrm{b}}$ \\ ${ }^{a}$ Instituto Superior de Engenharia de Lisboa, Rua Conselheiro Emídio Navarro, 1, 1959-007 Lisbon, Portugal \\ ${ }^{\mathrm{b}}$ Laboratório Nacional de Engenharia Civil, Avenida do Brasil 101, 1700-066 Lisbon, Portugal \\ ${ }^{\mathrm{c}}$ UNIC, Faculdade de Ciências e Tecnologia da UNL, 2829-516 Caparica, Portugal
}

\section{H I G H L I G H T S}

- The study shows the low variability of the mechanical properties of strands.

- During the period analysed (2001-2009) the properties did not show any trend.

- Generally, the results obtained agree with the results reported in PMC.

- However, some of the proposed models in the PMC should be updated.

\section{A R T I C L E I N F O}

\section{Article history:}

Received 15 January 2012

Received in revised form 16 April 2012

Accepted 29 April 2012

Available online 15 June 2012

\section{Keywords:}

Prestressing strands

Probabilistic models

Tensile strength

$0.1 \%$ proof stress

Modulus of elasticity

Bayesian statistics

\begin{abstract}
A B S T R A C T
This study focus on the probabilistic modelling of mechanical properties of prestressing strands based on data collected from tensile tests carried out in Laboratório Nacional de Engenharia Civil (LNEC), Portugal, for certification purposes, and covers a period of about 9 years of production. The strands studied were produced by six manufacturers from four countries, namely Portugal, Spain, Italy and Thailand. Variability of the most important mechanical properties is examined and the results are compared with the recommendations of the Probabilistic Model Code, as well as the Eurocodes and earlier studies. The obtained results show a very low variability which, of course, benefits structural safety. Based on those results, probabilistic models for the most important mechanical properties of prestressing strands are proposed.
\end{abstract}

(C) 2012 Elsevier Ltd. All rights reserved.

\section{Introduction}

The properties of prestressing strands have a considerable influence on the safety of prestressed structures, in particular bridges, as well as on the total construction cost. For this reason, it is fundamental to define adequately the mechanical properties of these elements. In this study, a statistical analysis of three families of strands with nominal diameters of 13.0, 15.2 and $15.7 \mathrm{~mm}$ (cross-section areas of 100,140 and $150 \mathrm{~mm}^{2}$, respectively) is presented. All strands have nominal tensile strength of $1860 \mathrm{MPa}$ (Y1860 grade) and are all composed by seven wires. The analysed strands correspond to the most widely used world wide in the last decades.

Samples were collected from tensile tests performed between 2001 and 2009 in Laboratório Nacional de Engenharia Civil (LNEC), Portugal. During this period, over 500 tensile tests were carried out for the three families mentioned above. However, several of

\footnotetext{
* Corresponding author. Tel.: +351 969401576; fax: +351218317021.

E-mail address: ljacinto@dec.isel.ipl.pt (L. Jacinto).
}

these tests refer to strands produced from the same heat (same casting). As it is known, the variability within a single heat is lower than the variability between different heats. Thus, for the purpose of statistical analysis, only one test from each heat was selected (at random), which reduced the sample to 131 tests.

Differently to what was done in a previous study [1], where stresses were computed dividing the forces measured in those tests by the actual strands cross-section areas, in the present study all the stresses were computed using nominal cross-section areas. This is common practice $[2,4]$.

For each of the three families of strands, the studied properties were: tensile strength or maximum stress $\left(f_{p}\right), 0.1 \%$ proof stress $\left(f_{p 0.1}\right)$, total elongation at maximum force $\left(\varepsilon_{u}\right)$ and modulus of elasticity $\left(E_{p}\right)$. It was found out that the difference in the mean of those properties between families was of the same order of magnitude as the standard deviations, which allowed us to consider the three families of strands as belonging to the same population. The three families were thus merged into a single sample.

The tested strands came from six manufacturers of different countries, including Portugal, Spain, Italy and Thailand. However, 
as it will be seen, the variability of the studied properties is very small, not justifying thus a separated analysis by manufacturer.

Fig. 1 shows a typical stress-strain diagram for a prestressing strand, with the corresponding mechanical properties indicated. The characteristic value of those properties (which are random variables), usually the 0.05 -quantile, is denoted adding the letter $k$ in lower script. For example, the characteristic value of the variable $f_{p 0.1}$ will be denoted by $f_{p 0.1 k}$. As shown in Fig. 1, prestressing strands do not exhibit a distinct yield point, which is typical of high strength steels, presenting however a slight inflection in the beginning of the hardening zone.

As stated above, the studied strands are all of the Y1860 grade, which has been the most commonly used in Portugal and in other countries. The value 1860 is termed nominal tensile strength, expressed in $\mathrm{MPa}$, and corresponds to the characteristic value of the tensile strength $f_{p}$, that is, $f_{p k}=1860 \mathrm{MPa}$ [2].

The main purpose of this study is to analyse the variability of the mentioned mechanical properties of prestressing strands and compare it with the corresponding recommendations of the Probabilistic Model Code [5] and other sources. Based on this comparison, probabilistic models for the mechanical studied properties are proposed.

\section{Critical review of the Probabilistic Model Code recommendations}

Table 1 shows the recommendations of the Probabilistic Model Code (PMC) [5] concerning the tensile strength $f_{p}$, modulus of elasticity $E_{p}$ and total elongation at maximum force $\varepsilon_{u}$ of prestressing steels. As it can be observed, PMC presents two expressions for the mean of $f_{p}$, one of which assumes constant coefficient of variation and the other constant standard deviation. PMC gives no indication about which one should be used.

Regarding the $0.1 \%$ proof stress, PMC recommends for strands the model: $f_{p 0.1}=0.85 f_{p}$, which assumes a perfect correlation between $f_{p}$ and $f_{p 0.1}$. As it will be seen, this model deserves some reservations, and an alternative model is proposed in this study.

\section{Statistical analysis of the available sample}

This section presents the results of the statistical analysis performed and produces some comments on its relevance for the structural safety. It must be emphasised that the stresses were computed for all cases dividing the forces obtained from the tests by the nominal cross-section area of the strands, as it is usual [2]. In this way, the variability of the computed stresses $\left(f_{p}\right.$ and $\left.f_{p 0.1}\right)$ already includes the variability of the cross-section area. Thus, in the model $F_{p}=f_{p 0.1} \cdot A_{p}$, which gives the force in a cable, the area of the

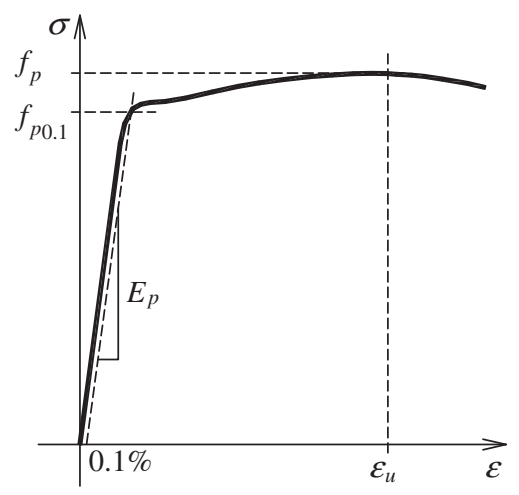

Fig. 1. Typical stress-strain diagram for a prestressing strand.
Table 1

Prestressing steels. Recommendations of the Probabilistic Model Code [5].

\begin{tabular}{llllll}
\hline Variable & & Mean & Std. dev. & $V^{\mathrm{a}}$ & Distribution \\
\hline$f_{P}$ & & $1.04 f_{p k}$ or & - & 0.025 & Normal \\
& & $f_{p k}+66 \mathrm{MPa}$ & $40 \mathrm{MPa}$ & - & \\
$E_{P}$ & Wires & $200 \mathrm{GPa}$ & - & & \\
& Strands & $195 \mathrm{GPa}$ & - & 0.02 & Normal \\
& Bars & $200 \mathrm{GPa}$ & - & & \\
$\varepsilon_{u}$ & & 0.05 & 0.0035 & - & Normal \\
\hline
\end{tabular}

a Coefficient of variation.

cable $A_{p}$ must be modelled as deterministic. Nevertheless, the variability of the cross-section area is also analysed.

As mentioned earlier the three samples of strands (diameters of $13,15.2$ and $15.7 \mathrm{~mm}$ ) were merged into a single sample. For a better appreciation of this aspect, Table 2 presents statistical summaries, separated for each family. As it can be seen, for all properties the difference in the means between families is of the same order of magnitude, or even lesser, as the standard deviation within each family. Moreover, the standard deviation, maximum and minimum values observed within each family are also very close across families. Therefore, there is no need to develop separated probabilistic models for each diameter. Merging the three samples into a single sample, the results become independent of the diameter.

\subsection{Tensile strength}

Fig. 2 shows the histogram of the tensile strength $f_{p}$ of the tests available (131 tests). As it can be seen, the normal model fits well the histogram, which agrees with the PMC recommendations [5] and the prEN 10138-1 [2]. The coefficient of variation obtained is very low, $V=0.018$.

According to the parameters obtained ( $\mu=1933 \mathrm{MPa}$, $\sigma=35 \mathrm{MPa}$ ), the characteristic value of $f_{p}$ can be estimated as $f_{p k}=1933-1.645 \times 35=1875 \mathrm{MPa}$, which satisfies the specified value for the $\mathrm{Y} 1860$ grade. The estimate of $f_{p k}$ using directly the sample available (i.e., empirical distribution) is $1881 \mathrm{MPa}$.

These results agree with the results reported by other authors, namely Casas and Sobrino [6], Nowak and Szerszen [7], and Wisniewski et al. [8]. The value of $40 \mathrm{MPa}$ for the standard deviation, as suggested by PMC, seems a reasonable assumption. So, for modelling the tensile strength the following model can be used:

$f_{p} \sim N(\mu, \sigma) ; \quad \mu=f_{p k}+1.645 \times 40(\mathrm{MPa}) ; \quad \sigma=40 \mathrm{MPa}$

Fig. 2b shows the values of the tensile strength $f_{p}$ by production year, indicating that there is no trend during the observed period (2001-2009). This Figure also suggests that the sample is free of outliers.

\subsection{The $0.1 \%$ proof stress}

From the structural safety point of view, the $0.1 \%$ proof stress $f_{p 0.1}$ is more decisive than the tensile strength, because this one is only reached for large strains, rarely observed in real structures, even for ultimate limit states.

Fig. 3 shows the histogram for the $0.1 \%$ proof stress and its temporal variation. As it can be seen, the $0.1 \%$ proof stress has greater variability $\left(\sigma_{f p 0.1}=51 \mathrm{MPa}\right)$ than the tensile strength $\left(\sigma_{f p}=35 \mathrm{MPa}\right)$, which agrees with results reported in earlier studies [6,8,9]. In fact the $0.1 \%$ proof stress is more sensitive than the tensile strength, because it depends on the measured modulus of elasticity and the curvature of the stress-strain diagram where the yielding starts. This finding raises a comment on the model $f_{p 0.1}=0.85 f_{p}$ proposed by PMC. According to this model the standard deviation of the $0.1 \%$ 
Table 2

Statistical summaries for each family of strands.

\begin{tabular}{llllllll}
\hline $\begin{array}{l}\text { Nominal } \\
\text { diameter }\end{array}$ & $\begin{array}{l}\text { Sample } \\
\text { size }\end{array}$ & Statistic & $\begin{array}{l}A_{p} \\
\left(\mathrm{~mm}^{2}\right)\end{array}$ & $\begin{array}{l}E_{P} \\
(\mathrm{GPa})\end{array}$ & $\begin{array}{l}\varepsilon_{u} \\
(\%)\end{array}$ & $\begin{array}{l}f_{p 0.1} \\
(\mathrm{MPa})\end{array}$ & $\begin{array}{l}f_{p} \\
(\mathrm{MPa})\end{array}$ \\
\hline \multirow{3}{*}{13} & & Mean & 100 & 201 & 5.8 & 1743 & 1945 \\
& \multirow{2}{*}{19} & Std & 0.9 & 3.6 & 0.4 & 49.2 & $\begin{array}{l}39.7 \\
\end{array}$ \\
& & Min & 99 & 194 & 4.4 & 1654 & 1878 \\
& Max & 102 & 208 & 6.2 & 1858 & 2008 \\
\hline \multirow{3}{*}{15.2} & & Mean & 141 & 199 & 5.9 & 1730 & 1943 \\
& \multirow{2}{*}{59} & Std & 1.0 & 4.1 & 0.3 & 42.4 & 30.0 \\
& & Min & 138 & 189 & 4.8 & 1626 & 1866 \\
& & Max & 143 & 209 & 6.9 & 1813 & 2004 \\
\hline \multirow{3}{*}{15.7} & & Mean & 152 & 197 & 5.7 & 1691 & 1916 \\
& \multirow{2}{*}{53} & Std & 1.3 & 4.5 & 0.3 & 50.3 & 33.8 \\
& & Min & 148 & 187 & 4.0 & 1558 & 1846 \\
& & Max & 156 & 205 & 6.6 & 1814 & 2014 \\
\hline
\end{tabular}

proof stress is smaller than the standard deviation of the tensile strength, contrarily to the results obtained. Later in this article a model for obtaining $f_{p 0.1}$ from $f_{p}$ based on regression analysis will be proposed, which allows overcoming this limitation.

According to the results presented in Fig. 3, the characteristic value of $f_{p 0.1}$ can be estimated as $f_{p 0.1 k}=1716-1.645 \times 51=1632 \mathrm{MPa}$. The ratio between $f_{p 0.1 k}$ and $f_{p k}$ is then $1632 / 1860=0.88$, which agrees with prEN10138-3 [3]. The ratio between the mean of $f_{p 0.1}$ and $f_{p k}$ is 1716/ $1860=0.92$. Regarding the coefficient of variation, the obtained value $(V=0.03)$ is similar to the results reported by Wiśniewski et al. [8]. Therefore, based on these considerations, the following model is proposed:

$f_{p 0.1} \sim N(\mu, \sigma) ; \quad \mu=0.90 f_{p k} ; \quad \sigma=50 \mathrm{MPa}$

\subsection{Total elongation at maximum force}

Total elongation at maximum force $\varepsilon_{u}$, undoubtedly an important parameter for the structural safety, does not generally raises concerns since typical values of this parameter (mean value above $5 \%$, as shown in Fig. 4) provide a rotation capacity of concrete sections in plastic domain higher than what is usually required in plastic analysis. Indeed, even for strains relatively high during tensioning operations (for example strains of about $0.7 \%$ ), the increase in strain necessary to reach failure would be $5 \%-0.7 \%=4.3 \%$, which would correspond to very high plastic deformations in concrete members.

It is interesting to note that the prestressing strands meet the requirements of high ductility (class B) as specified in EN 1992-1-1:2004 [4], Annex C, for reinforcing steels. In fact, the characteristic value of $\varepsilon_{u}$ (0.10-quantile, according to that Standard) is $\varepsilon_{u k}=5.8 \%-1.28 \times 0.4 \%=5.3 \%$, which is greater than $5.0 \%$ and $\left(f_{p} / f_{p 0.1}\right)_{k}$ is greater than 1.08 .

Fig. 4 shows the histogram of the $\varepsilon_{u}$ as well as its variation over last decade. Comparing the obtained values (mean and standard deviation) with the recommendations of the PMC, these seem reasonable. The histogram, which appears relatively symmetrical, supports the recommendation of PMC that suggests a normal distribution. The graphic (b) shows no temporal trend, and the minimum and maximum values observed did not seem to be outliers. It is noted that the available sample satisfies the requirement $\varepsilon_{u} \geqslant 3.5 \%$ specified in prEN 10138-1 [2].

Other authors, namely Casas and Sobrino [6] and Wiśniewski et al. [8], report results compatible with the results obtained in this study. Based on those results, the following model is proposed:

$\varepsilon_{u} \sim N(\mu, \sigma) ; \quad \mu=5 \% ; \quad \sigma=0.4 \% ; \quad(V=0.08)$ (a)

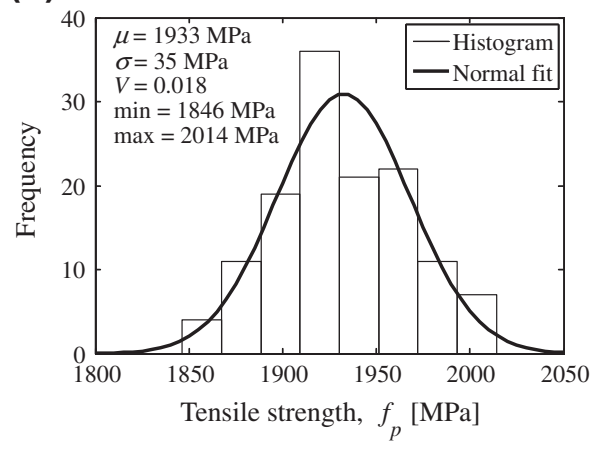

(b)

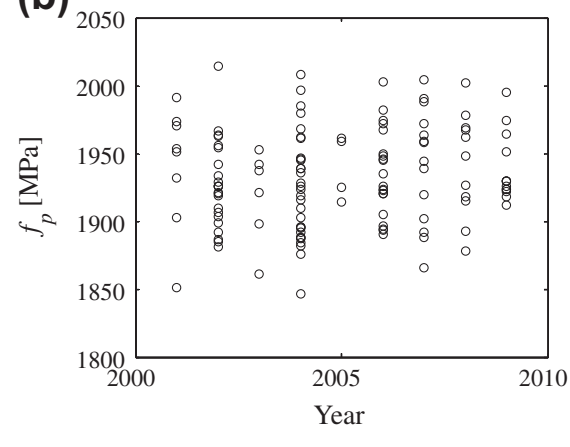

Fig. 2. Tensile strength $f_{p}$. (a) Histogram. (b) Values of $f_{p}$ by year. Each dot corresponds to a tensile test.

(a)

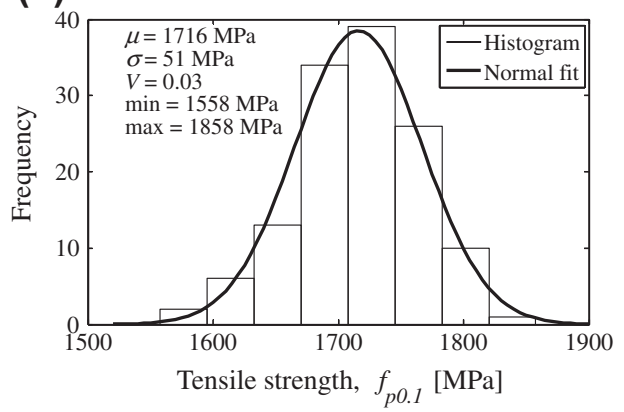

(b)

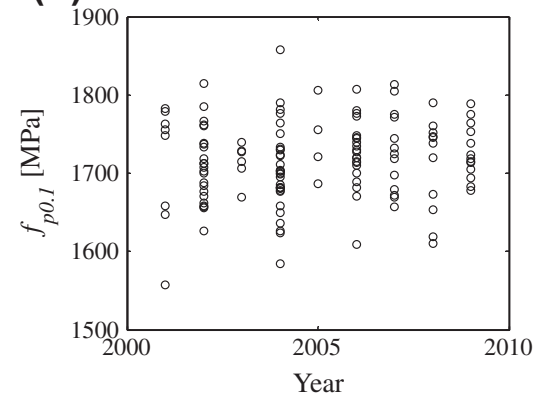

Fig. 3. The $0.1 \%$ proof stress, $f_{p 0.1}$. (a) Histogram. (b) Values of $f_{p 0.1}$ by production year. 
(a)

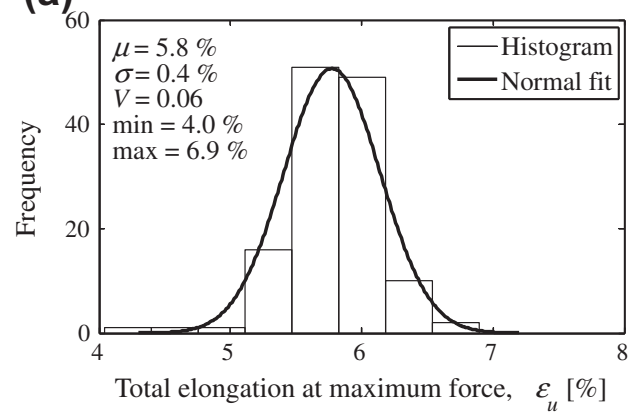

(b)

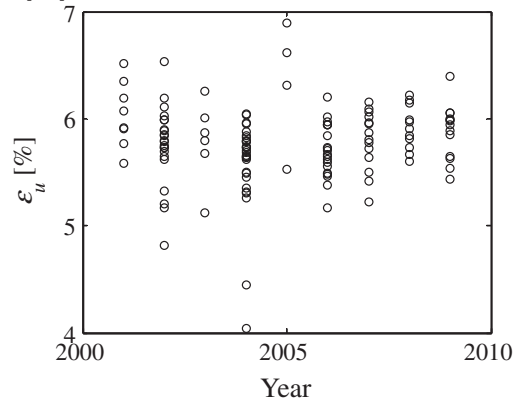

Fig. 4. Total elongation at maximum force, $\varepsilon_{u}$. (a) Histogram. (b) Values of $\varepsilon_{u}$ by production year.

(a)

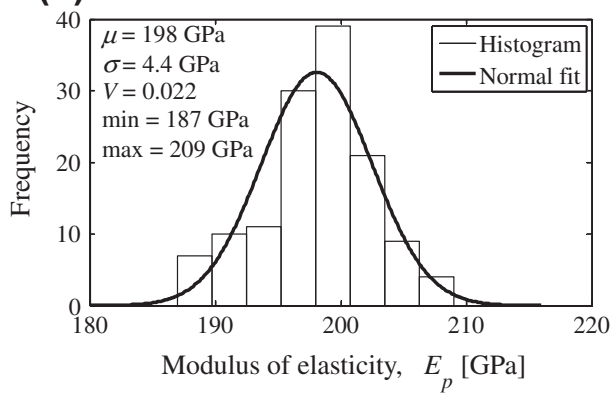

(b)

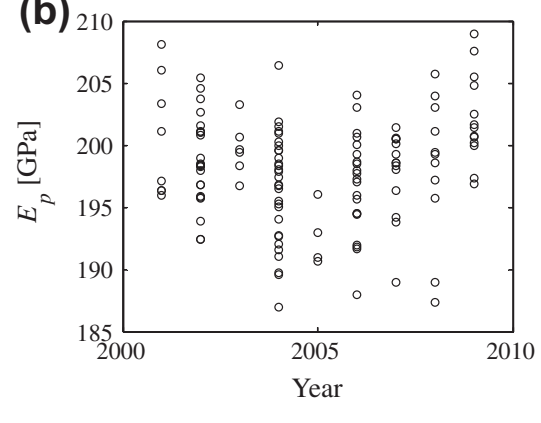

Fig. 5. Modulus of elasticity $E_{p}$. (a) Histogram. (b) Values of $E_{p}$ by year. Each dot corresponds to a tensile test.

\subsection{Modulus of elasticity}

Accurate knowledge on the actual value of the modulus of elasticity is important especially during tensioning operations, since one of the criteria for controlling the actual applied prestressing force is made by measuring the tendon elongations, which, of course, depend on the modulus of elasticity. However, regarding safety checking, this is a parameter of some importance with regard to serviceability limit states, namely decompression limit state and cracks width, having however little effect on ultimate limit states, since when these are reached the steel are in general in plastic domain.

Fig. 5 shows the histogram of the modulus of elasticity $E_{p}$ and its temporal variation during the observed period. The histogram suggests that the normal model is adequate to describe $E_{p}$, as recommended by PMC [5]. For strands both PMC and EN 1992-1-1 [4] recommend an average value of $195 \mathrm{GPa}$. The mean of the sample available in this study is higher than this value, although the difference is small (1.5\%). For the coefficient of variation, the PMC recommends 0.02 , which corresponds to a standard deviation of 3.9 MPa, that is $11 \%$ lower than the value obtained ( $4.4 \mathrm{GPa}$ ). Thus, maintaining the usual recommendation for the mean value equal to $195 \mathrm{GPa}$, the results suggests that a higher standard deviation than that recommended by PMC should be adopted, for example $5 \mathrm{GPa}$. In short, the following model is proposed:

$$
E_{p} \sim N(\mu, \sigma) ; \quad \mu=195 \mathrm{GPa} ; \quad \sigma=5 \mathrm{GPa} ; \quad(V=0.025)
$$

Although different authors observed dependence between the geometric properties and the modulus of elasticity, in particular for steel profiles [16], no such dependence was observed in the data analysed, as shown in Table 2.

\subsection{Cross-section area}

As mentioned earlier, the proposed models for stresses $\left(f_{p}\right.$ or $f_{p 0.1}$ ) already include the variability of the cross-section area. So, adopting those models in reliability analysis, the cross sectional area must be modelled as a deterministic variable. However, it is worth analysing the variability of this parameter, and for this purpose there is no inconvenience in using samples from the same heat. Therefore, all samples were used. Table 3 shows some statistics concerning the three samples of strands available. As it can be seen, the coefficients of variation of the cross-section areas are very small. Fig. 6 shows the histogram of the family $15.2 \mathrm{~mm}$. As it can be seen, the Normal model fits well the histogram.

According to prEN10138-1 [2], the tolerance concerning the mass per meter for strands is $\pm 2 \%$ of its nominal value. This requirement is generally satisfied by the samples analysed.

\subsection{Correlation analysis}

\subsubsection{Correlation between $0.1 \%$ proof stress and tensile strength}

Fig. 7 shows the scatter diagram of points $\left(f_{p}, f_{p 0.1}\right)$ regarding the sample of 131 tensile tests studied. A linear regression analysis

Table 3

Sample statistics concerning the cross sectional area of the studied strands (tests performed between 2001 and 2009).

\begin{tabular}{llllllll}
\hline $\begin{array}{l}\text { Strand } \\
\text { family }\end{array}$ & $\begin{array}{l}\text { Nominal } \\
\text { area }\left(\mathrm{mm}^{2}\right)\end{array}$ & $\begin{array}{l}\text { Sample } \\
\text { Size }\end{array}$ & $\begin{array}{l}\text { Mean } \\
\left(\mathrm{mm}^{2}\right)\end{array}$ & $\begin{array}{l}\text { Std. dev. Coefficient } \\
\left(\mathrm{mm}^{2}\right)\end{array}$ & $\begin{array}{l}\text { Min } \\
\text { of variation }\end{array}$ & $\begin{array}{l}\text { Max } \\
\left(\mathrm{mm}^{2}\right) \\
\left(\mathrm{mm}^{2}\right)\end{array}$ \\
\hline $13.0 \mathrm{~mm}$ & 100 & 98 & 100 & 1.0 & 0.010 & 99 & 102 \\
$15.2 \mathrm{~mm}$ & 140 & 257 & 141 & 1.0 & 0.007 & 138 & 143 \\
$15.7 \mathrm{~mm}$ & 150 & 151 & 151 & 1.3 & 0.009 & 148 & 156 \\
\hline
\end{tabular}




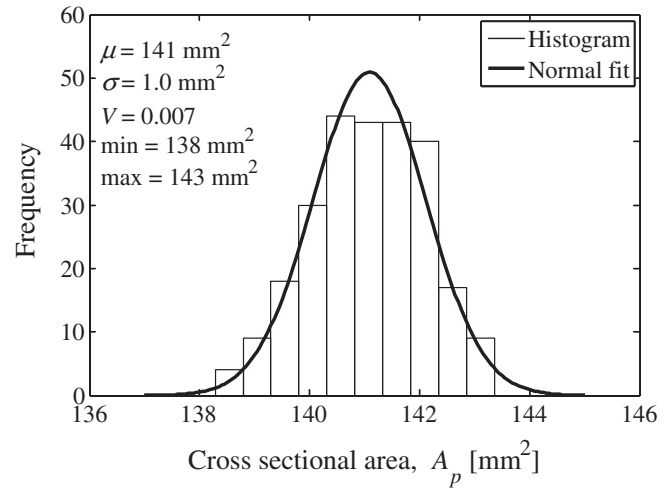

Fig. 6. Cross-section area histogram for strands with nominal diameter of $15.2 \mathrm{~mm}$.

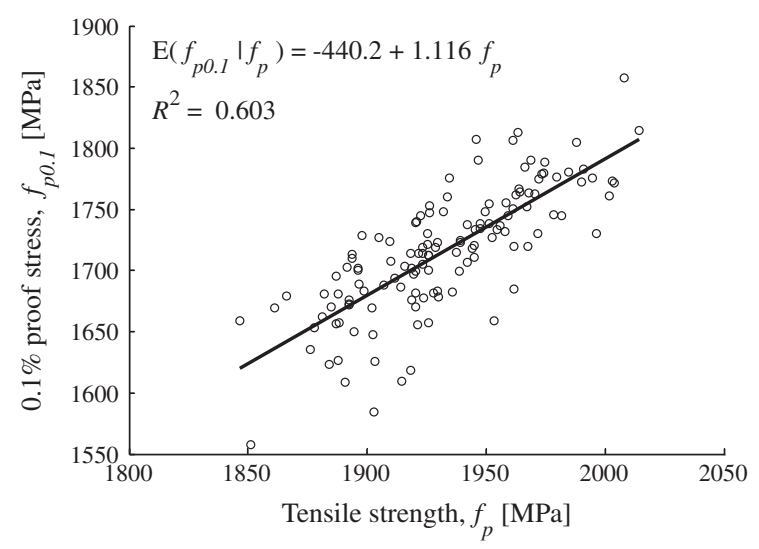

Fig. 7. Scatter diagram of points $\left(f_{p}, f_{p 0.1}\right)$.

was performed and the following regression parameters were obtained:

$\hat{\beta}_{0}=-440 \mathrm{MPa} ; \quad \hat{\beta}_{1}=1.12 ; \quad \hat{\sigma}=32 \mathrm{MPa}$,

where $\hat{\beta}_{0}$ and $\hat{\beta}_{1}$ represent estimates of the intercept and the slope of the straight line, respectively, and $\hat{\sigma}$ an estimate of the residuals standard deviation [10]. The parameter $\hat{\sigma}$ corresponds to the standard deviation of the difference between the observed values and the regression line. This is a measure of the uncertainty in the predictive model, and is fundamental in evaluating the correlation between different characteristics of steel. The coefficient of determination is $R^{2}=0.603$, which corresponds to a coefficient of correlation of 0.78 and indicates high correlation (but not perfect) between those two variables.

Based on the above regression model, the following probabilistic model can be used in case it is necessary to model simultaneously $f_{p 0.1}$ and $f_{p}$ :

$f_{p 0.1}=-440+1.12 f_{p}+32 Z(\mathrm{MPa})$

where $f_{p}$ must be given in MPa and $Z \sim N(0,1)$, which is rather different from the model $f_{p 0.1}=0.85 f_{p}$ proposed by PMC, which assumes a perfect correlation between the variables.

3.6.2. Correlation between total elongation at maximum force and tensile strength

The correlation between total elongation $\varepsilon_{u}$ and tensile strength $f_{p}$ was also analysed (Fig. 8). As observed the coefficient of determination is $R^{2}=0.005$, which corresponds to a coefficient of correlation of 0.07 . From a practical point of view, these results show that $\varepsilon_{u}$ and $f_{p}$ can be considered independent.

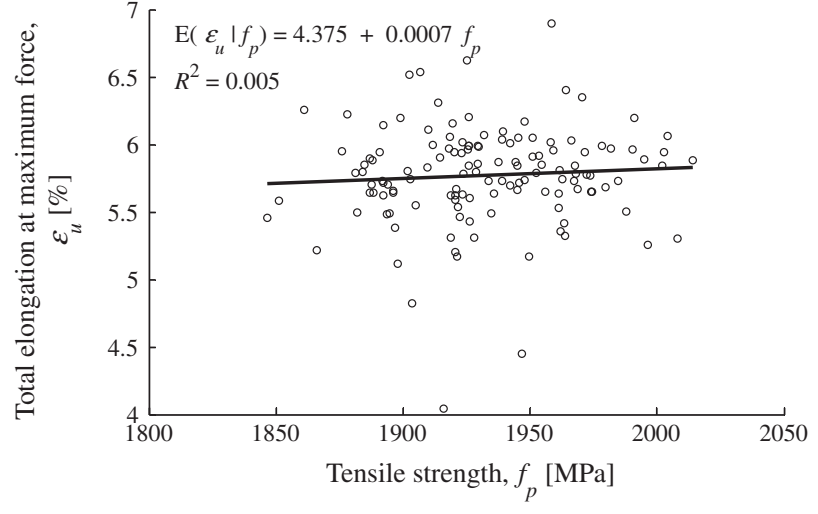

Fig. 8. Scatter diagram of points $\left(f_{p}, \varepsilon_{u}\right)$.

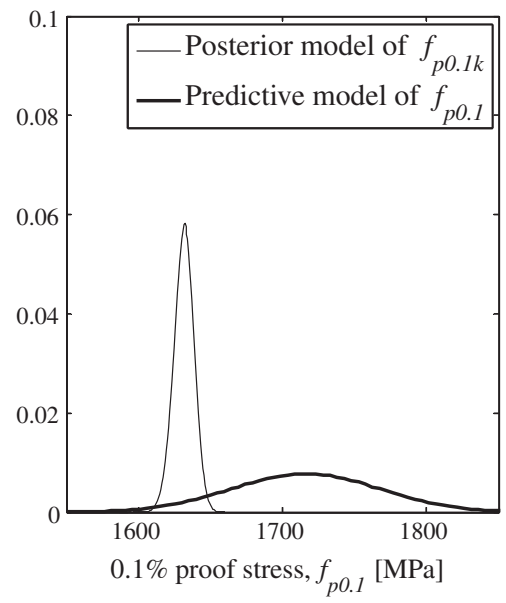

Fig. 9. Bayesian probabilistic models for $f_{p 0.1}$ and $f_{p 0.1 \mathrm{k}}$.

\section{Uncertainty induced by the limitation of the available sample size}

The results presented above were based on a sample of size 131 . This is not a very large sample and certainly induces uncertainty (statistical uncertainty). In this section, the effect of the sample size is analysed. The discussion focuses on the $0.1 \%$ proof stress, since it is one of the most important parameters studied. Remember that the characteristic value of this parameter was estimated in $1632 \mathrm{MPa}$. Obviously, this estimate is not error-free. In order to evaluate the error in this estimate, or, equivalently, to assess the goodness of the available sample size, the Bayesian paradigm will be adopted. This approach has been widely accepted as the most appropriate to deal with statistical uncertainty [11].

Since it was assumed that $f_{p 0.1}$ follows a normal distribution, i.e., $f_{p 0.1} \sim N(\mu, \sigma)$, an estimate of $f_{p 0.1 k}$ was computed using the following expression:

$f_{p 0.1 k}=\mu-1.645 \sigma$

According to the Bayesian paradigm the parameters $\mu$ and $\sigma$ are modelled as random variables [12]. Since $f_{p 0.1 k}$ is a function of $\mu$ and $\sigma$, it follows that $f_{p 0.1 k}$ is also a random variable. The standard deviation of $f_{p 0.1 k}$ constitutes a good measure of the error in the estimate $f_{p 0.1 \mathrm{k}}=1632 \mathrm{MPa}$.

Posterior Bayesian distributions for $\mu$ and $\sigma$ can be found in [12] or in [13]. According to those references, using non-informative priors, the parameter $\mu$ is t-distributed and $\sigma^{2}$ follows an inverted gamma distribution. Using those distributions a sample of $f_{p 0.1 \mathrm{k}}$ 
Table 4

Proposed probabilistic models for prestressing strands.

\begin{tabular}{llllll}
\hline Variable & Unit & Mean & Std. dev. & $V$ & Distribution \\
\hline$f_{p}$ & MPa & $f_{p k}+1.645 \times 40$ & 40 & - & Normal \\
$f_{p 0.1}$ & MPa & $0.90 f_{p k}$ & 50 & - & Normal \\
$\varepsilon_{u}$ & - & $5 \%$ & $0.40 \%$ & 0.08 & Normal \\
$E_{P}$ & $\mathrm{GPa}$ & 195 & 5 & 0.025 & Normal \\
\hline
\end{tabular}

Notes: (1) The model parameters are expressed as a function of $f_{p k}$, which represent the nominal value of the tensile strength. (2) The variables $f_{p 0.1}$ and $f_{p 0.1 k}$ are dependent on each other. In case it is necessary to model simultaneously both variables the Eq. (6) can be used.

was generated using Monte Carlo simulation from which the mean and the standard deviation were computed. The mean of $f_{p 0.1 \mathrm{k}}$ is $1632 \mathrm{MPa}$ and the standard deviation is $6.9 \mathrm{MPa}$, which yields a relative error of $6.9 / 1632=0.4 \%$. Since this is a very small error, it can be concluded that the estimate $f_{p 0.1 k}=1632 \mathrm{MPa}$ can be considered very close to the true value, or that the simple size can be regarded as good enough for the purpose of estimating $f_{p 0.1 \mathrm{k}}$.

The quantile 0.05 of $f_{p 0.1 k}$ was also computed and the value $1620 \mathrm{MPa}$ was obtained, that is, the probability that the true $f_{p 0.1 \mathrm{k}}$ is greater than $1620 \mathrm{MPa}$ is 0.95 . The fact that 1620 is close to 1632 indicates that the distribution of $f_{p 0.1 k}$ is quite narrow or that the uncertainty in $f_{p 0.1 \mathrm{k}}$ is small. This can be appreciated in Fig. 9, where the distribution of $f_{p 0.1 k}$ together with the predictive model of $f_{p 0.1}$ is presented. It is interesting to note that the Bayesian 0.05 -quantile of $f_{p 0.1 \mathrm{k}}(1620 \mathrm{MPa})$ coincides with the corresponding classical lower limit of the one-sided tolerance interval with confidence level of 0.95 and coverage probability of 0.95 [14,15].

\section{Conclusions}

The present study shows the low variability of the mechanical properties of prestressing strands, which, of course, benefits the safety of structures. The highest variability was obtained for the elongation at maximum force, which revealed a coefficient of variation of about 0.06 . For the remaining properties the coefficient of variation was lower than 0.03 .

The Bayesian analysis showed that the estimate of the characteristic value of the $0.1 \%$ proof stress can be considered accurate, that is, the uncertainty induced by the limitation of the sample at hand is relatively small. In addition it is believed that the available sample has a reasonable representativeness, so that it can be used for defining probabilistic models for the main mechanical properties of prestressing strands. Table 4 summarises the models proposed in this study.

The proposed models were based on the results obtained for strands of the Y1860 grade. Therefore, strictly speaking, they are valid only for that grade. However, if more accurate values for other grades are not known, those models can be applied. In effect, considering that the products of other grades differ only on its strength, and production techniques and quality control methods are common, and taking into account previous evidence gained at LNEC, it is acceptable to use the proposed models for other grades in the absence of better models and information.

It was demonstrated that the correlation between $0.1 \%$ proof stress and tensile strength is strong. On the other hand, the correlation between tensile strength and total elongation at maximum force can be neglected.

Generally, the results reported in the article agree with the results reported in earlier studies and in the PMC [5]. However, some of the proposed models in the PMC should be updated, including the assumption of perfect correlation between proof stress and tensile strength. For the remaining properties, it was concluded that the recommendations of the PMC are still valid, despite it is based on studies carried out three decades ago. In particular, the analysis of the available data showed no evidence that non-Gaussian distributions should be used to characterise prestressing steel.

\section{Acknowledgments}

Authors thank the support received from Instituto Superior de Engenharia de Lisboa, and also the partially funding by Fundação para a Ciência e Tecnologia, through Grant SFRH/BD/45022/2008.

\section{References}

[1] Jacinto L, Pipa M, Santos L, Neves L. Statistical analysis of mechanical properties of prestressing strands. In: Proceedings of the 11th international conference on applications of statistics and probability in soil and structural engineering, ICASP 11, Zurich; 2011.

[2] prEN10138-1:2009. Prestressing steels - Part 1: general requirements. CEN Brussels; 2009 .

[3] prEN10138-3:2009. Prestressing steels - Part 3: strand. CEN, Brussels; 2009.

[4] EN 1992-1-1:2004. Eurocode 2: design of concrete structures - Part 1-1: general rules and rules for buildings, CEN, Brussels; 2004.

[5] JCSS. Probabilistic Model Code. Joint committee on structural safety, <http:// www.jcss.ethz.ch>, 12th draft; 2001.

[6] Casas JR, Sobrino JA. Geometrical and material uncertainties in reinforced and prestressed concrete bridges. In: Proceedings of structures congress XIII, ASCE, Boston; 1995. p. 1462-1465.

[7] Nowak AS, Szerszen MM. Calibration of design codes for buildings, ACI 318: Part 1 - statistical models for resistance. ACI Struct J 2003;100:377-82.

[8] Wiśniewski D, Cruz P, Henriques A, Simões R. Probabilistic models for mechanical properties of concrete, reinforcing steel and pre-stressing steel. Struct Inf Eng 2012;8:111-23.

[9] Strauss A. Stochastische modellierung und zuverlassigkeit von betonkonstruktionen. PhD Thesis. University of Applied Science and Natural Resources, Vienna, Department of Civil Engineering and Natural Hazards; 2003

[10] Ang A, Tang WH. Probability concepts in engineering. 2nd ed. Chichester: John Wiley \& Sons; 2007.

[11] Engelund S, Rackwitz R. On predictive distribution for the three asymptotic extreme value distributions. Struct Saf 1992;11:255-8.

[12] Bernardo JM, Smith AFM. Bayesian theory. John Wiley \& Sons; 2000.

[13] Paulino CD, Turkman MA, Murteira B. Bayesian statistics. Fundação Calouste Gulbenkian, Lisboa; 2003 [in Portuguese].

[14] Montgomery DC, Runger GC. Applied Statistics and probability for engineers. 4th ed. John Wiley \& Sons; 2007.

[15] ISO 12491:1997. Statistical methods for quality control of building materials and components. International Organization for Standardization, Switzerland; 1997.

[16] Strauss et al. Technologischeeigenschaften von stählenimeuropäisc henvergleich. Ernst \&SohnVerlagfürArchitektur und technischeWissens chaften GmbH \& Co. KG, Berlin. Stahlbau 75, Heft 1, 2006. 